\title{
Gamification and sustainable consumption: overcoming the limitations of persuasive technologies
}

Huber, Martina Z ; Hilty, Lorenz M

\begin{abstract}
The current patterns of production and consumption in the industrialized world are not sustainable. The goods and services we consume cause resource extractions, greenhouse gas emissions and other environmental impacts that are already affecting the conditions of living on Earth. To support the transition toward sustainable consumption patterns, ICT applications that persuade consumers to change their behavior into a "green" direction have been developed in the field of Persuasive Technology (PT). Such persuasive systems, however, have been criticized for two reasons. First, they are often based on the assumption that information (e.g., information on individual energy consumption) causes behavior change, or a change in awareness and attitude that then changes behavior. Second, PT approaches assume that the designer of the system starts from objective criteria for "sustainable" behavior and is able to operationalize them in the context of the application. In this chapter, we are exploring the potential of gamification to overcome the limitations of persuasive systems. Gamification, the process of using game elements in a non-game context, opens up a broader design space for ICT applications created to support sustainable consumption. In particular, a gamification-based approach may give the user more autonomy in selecting goals and relating individual action to social interaction. The idea of gamification may also help designers to view the user's actions in a broader context and to recognize the relevance of different motivational aspects of social interaction, such as competition and cooperation. Based on this discussion we define basic requirements to be used as guidance in gamification-based motivation design for sustainable consumption.
\end{abstract}

DOI: https://doi.org/10.1007/978-3-319-09228-7_22

Posted at the Zurich Open Repository and Archive, University of Zurich

ZORA URL: https://doi.org/10.5167/uzh-109999

Book Section

Accepted Version

Originally published at:

Huber, Martina Z; Hilty, Lorenz M (2015). Gamification and sustainable consumption: overcoming the limitations of persuasive technologies. In: Hilty, Lorenz; Aebischer, Bernard. ICT Innovations for Sustainability. Cham: Springer, 367-385.

DOI: https://doi.org/10.1007/978-3-319-09228-7_22 


\title{
Gamification and Sustainable Consumption: Overcoming the Limitations of Persuasive Technologies
}

\author{
Martina Z. Huber ${ }^{1}$ and Lorenz M. Hilty ${ }^{1,2,3}$ \\ ${ }^{1}$ Department of Informatics, University of Zurich, Zurich, Switzerland \\ \{mhuber, hilty\}@ifi.uzh.ch \\ ${ }^{2}$ Empa, Swiss Federal Laboratories for Materials Science and Technology, St. Gallen, \\ Switzerland \\ ${ }^{3}$ Centre for Sustainable Communications CESC, KTH Royal Institute of Technology, \\ Stockholm, Sweden
}

\begin{abstract}
The current patterns of production and consumption in the industrialized world are not sustainable. The goods and services we consume cause resource extractions, greenhouse gas emissions and other environmental impacts that are already affecting the conditions of living on Earth. To support the transition toward sustainable consumption patterns, ICT applications that persuade consumers to change their behavior into a "green" direction have been developed in the field of Persuasive Technology (PT). Such persuasive systems, however, have been criticized for two reasons. First, they are often based on the assumption that information (e.g., information on individual energy consumption) causes behavior change, or a change in awareness and attitude that then changes behavior. Second, PT approaches assume that the designer of the system starts from objective criteria for "sustainable" behavior and is able to operationalize them in the context of the application.

In this chapter, we are exploring the potential of gamification to overcome the limitations of persuasive systems. Gamification, the process of using game elements in a non-game context, opens up a broader design space for ICT applications created to support sustainable consumption. In particular, a gamification-based approach may give the user more autonomy in selecting goals and relating individual action to social interaction. The idea of gamification may also help designers to view the user's actions in a broader context and to recognize the relevance of different motivational aspects of social interaction, such as competition and cooperation. Based on this discussion we define basic requirements to be used as guidance in gamificationbased motivation design for sustainable consumption.
\end{abstract}

Keywords: Gamification, Sustainable Consumption, Persuasive Technology, Technology Paternalism, Collaborative Software

This Accepted Author Manuscript is copyrighted by Springer. The final publication will be available via http://link.springer.com/bookseries/11156 by end of August 2014. Suggested citation: Huber, M.Z., Hilty, L.M.: Gamification and Sustainable Consumption: Overcoming the Limitations of Persuasive Technologies. In: Hilty, L.M., Aebischer, B. (eds.) ICT Innovations for Sustainability. Advances in Intelligent Systems and Computing 310. Springer International Publishing (2014, in press) 


\section{Introduction}

The goods and services consumed in industrial societies are the main cause of global environmental impact. Sustainable consumption and production aims at changing "unsustainable patterns of consumption and production" and requires "fundamental changes in the way societies produce and consume" in order to "achieve global sustainable development" [1, p. 12].

ICT applications have been developed to support users in this imperative change towards sustainable consumption. Specifically, eco-feedback technologies and socalled Persuasive Sustainability Systems (PSSs), which are Persuasive Technologies (PTs) in the field of sustainability, aim at inducing users to more sustainable behavior. Whereas eco-feedback technologies have primarily focused on raising awareness by providing information on measurable aspects of sustainability, PSSs go beyond this and suggest predefined actions typically designed to achieve a rational goal. Within current implementations these two technologies usually merge, as in the cases of UbiGreen [2], a mobile phone application supporting "green" choices of transport modes or features in Toyota cars which encourage eco-friendly driving [3]. Recently, community-based approaches encouraging environmentally friendly actions, particularly in regard to reducing residential electricity usage have increasingly been discussed within the field of ICT. Eco-feedback and PT have been expanded to the Internet, sharing usage data and comparing it with predefined benchmarks and social norms. Examples include WattsUp [4], which focuses on social norms and StepGreen.org [5], which additionally suggests actions that "may save money or energy" (p. 2).

In spite of the widely acknowledged desirability of encouraging sustainable behavior, PT has been criticized for several limitations. These involve, in particular, an oversimplified and isolated view on behavior due to focusing on clearly measurable aspects, the inherent technology paternalism and the lack of solution building [6] [7]. These limitations will be explained in more detail later.

The design of ICT solutions to support people in behavior change needs to be approached in a more comprehensive way. Instead of focusing only on predefined solutions, the context of the process causing the consumption has to be analyzed. This requires additional engagement strategies, the (social) context of an action and the user's cognitive, emotional and social capabilities. Research has shown that games have a high potential for engaging people in a wide variety of ways.

Games tap into the world of "fun", affect emotions and have the ability to involve users more deeply. At the same time they have the potential to motivate users toward a specific course of action without dogmatism [6]. Gamification is the use of game or game design elements in non-game contexts and has recently become of increasing interest within ICT. "Assuming that people like to play but are confronted in their everyday life with non-motivational activities, gamification is the process that induces motivation in those activities" [8, p. 3]. Gamification does not say anything about how to use game elements in the non-game context or what the non-game context has to be. As a result gamification-based approaches can be found in a wide range of applications. Approaches include loyalty programs (e.g. collecting miles in frequent- 
flyer programs or stamps in super markets), systems encouraging customers to share information (e.g. showing progress bars and scores such as in LinkedIn [9] and ResearchGate [10]), or motivating consumers to eco-friendly driving behavior (e.g. providing information on average consumption as Toyota does [3]) or to reduce electricity consumption (e.g., by enabling normative comparison as done by Opower [11]).

As a matter of fact, all of these gamification-based approaches are rooted in PTbased design. Depending on the perspective, it could also be argued that recent PTbased approaches include gamification-based ideas (see for example [2], [3], and [4]). Regardless of where the line between PT and gamification is drawn, all the examples previously mentioned inherit the limitations of PT-based design.

In this chapter, we elaborate requirements intended to guide the design of a gamification-based approach, which motivates sustainable consumption while overcoming the present limitations of PT. Sustainable consumption is embedded in, and influenced by, a complex structure of regulations, communities, large enterprises, and other stakeholders. All of these entities affect a consumer's decision-making process and in their turn may be influenced by it. We believe that in order to achieve sustainable consumption it is important to take into account the influences of all these entities. Our research focuses on the potential role of gamification in this context.

The chapter is organized as follows: Section 2 provides some background on PT and discusses the major limitations of PT; we focus on limitations we consider to be relevant, at least in the context of sustainable consumption. Section 3 gives an overview of gamification. Section 4 provides examples of first attempts to introduce gamification into the field of sustainable consumption. Section 5 elaborates basic requirements for gamification-based approaches to sustainable consumption that can guide designers who want to overcome the limitations of PT-based approaches. Finally, section 6 provides preliminary conclusions and identifies open research questions.

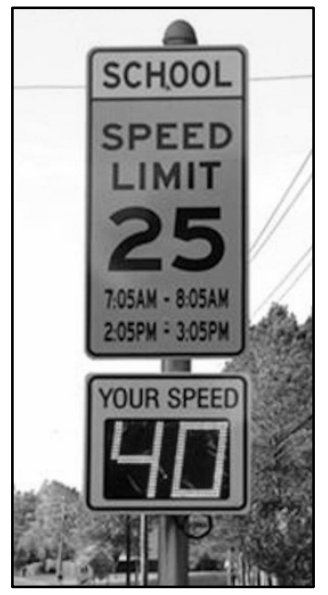

Fig. 1. Information comparison as a persuasion technique (Source: [12]) 


\section{Persuasive Technology}

\subsection{Background}

The concepts we introduce below are based on Fogg's work on captology [14] - the study of computers as persuasive technology.

Persuasion. Fogg defines persuasion as "an attempt to change attitudes or behavior or both (without using coercion or deception)" (p. 15). Thereby, intention to change attitudes or behaviors is seen as a necessary condition for persuasion. The goal of persuasion is to generate intentionally planned attitude and behavior changes [14], [13]. "Self-persuasion" is a specific form of persuasion in which a person already agrees with the values directing the behavior change and the persuasive system is used in order to "overcome a weakness of the will" [15, p. 645].

Persuasive Systems. Based on the definition of "persuasion", PT can be defined as an "interactive computer system [technology] designed to change people's attitudes and behaviors" [13, p. 1]. Thereby, PT "focuses on the attitude and behavior changes intended by the designers of interactive technology products" [13, p. 17]. As an example, Fig. 1 shows a speed monitoring system. The underlying goal is to raise drivers' awareness of their speed and implicitly suggesting driving at the maximal indicated speed limit. Specific applications of PT are usually called "persuasive systems". The application of PT in the domain of ecological sustainability has created the special case of "persuasive sustainability systems" (PSSs). Contemporary PSSs are described as "technologies that sense, interpret, and respond to human activity by providing information intended to change the behavior of individual consumers according to a metric selected in a top-down fashion usually defined as reducing resource consumption" [6, p. 950].

Eco-feedback Technology. Eco-feedback technology provides information (e.g. by mobile phones, ambient displays, or online visualizations) about individual or group behavior and its environmental effects. These applications are based on the assumption that their users lack awareness and understanding of the environmental effects of their everyday behavior [16, p. 1999]. Research on eco-feedback has its roots in environmental psychology and - as some authors claim - may improve PT research [16]. Whereas eco-feedback systems have the character of raising awareness, PSSs tend to persuade consumers to change their behavior in order to achieve a specific system goal.

Communicating with vs. Communicating through Computers. Persuasive and eco-feedback technologies are important in human-computer interaction (HCI) research. In HCI, the focus is mainly on people's interaction with computer systems [13]. Fogg makes a distinction between this view and the paradigm of computermediated communication (CMC). In the first case, the system is viewed as a "participant in the interaction and possible source of persuasion", able to "proactively 
seek to motivate and influence users, drawing on strategies and routines programmed into it [e.g. by incentives or negotiations]." [13, p. 16].

In the second case, the focus is on people's interaction through computer systems, which are used "as a channel that allows humans to interact with each other (e.g. instant messaging and electronic whiteboards for collaboration)" [13, p.16]. While captology - the study of computers as persuasive technology - investigates how people are persuaded when interacting with computers, we consider that both aspects are equally relevant to a gamification-based approach.

The Scope of Consumption. Consumer behavior has been a subject of research in the fields of evolutionary psychology, anthropology and sociology. In a nutshell, there is high evidence that consumer behavior is mainly influenced by

- Symbolic roles and cultural meanings of consumer goods (e.g. McCracken in [17])

- Social and sexual competition (e.g. Penn in [18])

- Continual process of constructing and reconstructing personal identity (e.g. Soron in [19])

Individual decisions and actions are rooted in routines and based on affective and emotional bursts. They evolve from the complex structure of socio-cultural and socioeconomic influences and rely on restrictions due to constraints (e.g. regulations) or current unavailability of possibilities (e.g., due to low income).

PT is usually based on the implicit assumption that information causes behavior change - or at least a change in awareness and attitude that will then cause behavior change. Against the background of the views cited, this looks like a reversion to the era of psychological behaviorism.

\subsection{Limitations of PT-based Approaches to Sustainable Consumption}

In this subsection, we present an overview of aspects of PT-based approaches discussed in the literature with a focus on issues we consider particularly limiting in the context of sustainable consumption.

Focus on Measurable Effects. PT-based approaches applied in the field of sustainability usually rely on measurable effects declared as sustainability indicators, for example how much of a resource such as electric energy has been used. The measured data, typically in regard to a benchmark, usually works as a trigger for system actions (e.g. a list of predefined "solutions" such as turning off the lights), with the intention of persuading consumers to move toward the system goal (such as reducing energy consumption).

Measurements are becoming more and more fine-grained, allowing more tailored interventions by PT. In the domain of residential electricity consumption, an approach called Non-Intrusive Load Monitoring (NILM) is becoming popular. The goal of NILM is to recognize household appliances based on their "energy signature". Machine learning algorithms applied for this purpose have been improved over the last years. However, accuracy is still an issue, especially if appliances are new and/or 
have similar signatures [20] (e.g., dryer and oven [21]). Furthermore, satisfactory answers to privacy concerns are still missing [22].

Despite improvements in such technologies, with a too narrow focus on measured output, even with $100 \%$ accuracy in NILM, interpretation of the meaning attached to an action (e.g. reason, intention and kind of action) and analysis of the process causing the consumption become very difficult or even impossible.

Assumption of Rational Choice. PT-based approaches are often based on the implicit assumption that consumers are rational actors whose only goal is to optimize their activities based on their preferences and knowledge [6]. "Rational choice models assume that human behavior is regulated by a systematic process of evaluating expected utility." [16, p. 2000]. Under this assumptions rational actors in any given situation only take actions that provide the biggest personal gain at the least personal cost. Evidence shows that "ordinary people in ordinary situations are simply not capable of processing all the cognitive information required for so-called 'rational' choices." [23, p. 36]. Benkler [24] argues that under the homo economicus assumption, volunteer work for peer-production projects such as Wikipedia [25] would not exist. Even though there are people who show a behavior based on purely selfish choices - a limited form of rational choice -, research has shown that this applies to only one third of the population [24].

Feeding back data from measurable aspects of sustainability makes sense under the assumption of purely rationally motivated consumers. However, consumers are diversely motivated, and the interpretation of change in measured output under the isolated assumptions of rational choices loses sight of the broader motivational aspects of human behavior, and may lead to ineffective action triggers produced by the system (e.g. predefined "solutions" which have no meaning to consumer).

Insufficient Account of Individual Differences and Social Context. PT-based approaches are for the most part built on a foundation that information will trigger a predetermined interpretation and action in all consumers. This assumption can only be made if consumers are seen as identical and isolated agents. In reality, though, consumers come with a "variety of backgrounds, desires, and skillsets" [26, p. 225] and their decisions are influenced by their individual and collective identity. Identity in this context is "the meanings one has as a group member, as a role-holder, or as a person" and part of the self which emerges from social interactions [27, p. 8]. According to Greenwald and Pratkanis [28], the self consists of three different aspects:

- public: 'people [parents, peers, authorities] think I...',

- private: 'I [my inner audience for behavior] think I...',

- collective: 'my family [reference group] thinks I...'.

The development and influential power of these aspects depend on cultural variation, specifically on the complexity, the level of individualism, and the looseness of a culture. Based on this view of humanity, it can be assumed that the more all three dimensions are developed, the more likely it is that people will express their private 
self [29]. No individual self can exist without social relations. Mead views the self as "something which has a development; it is not initially there, at birth, but arises in the process of social experience and activity (...)" [30, p. 1]. Baumeister and Leary point out the importance of the need to belong, which "can be considered a fundamental human motivation" [31, p. 521].

Within the design structure of PT-based approaches, while focusing on measurable aspects of sustainability and assuming consumers are purely rationally motivated, it makes sense to consider consumers as uniform agents. However, ignoring the complex interaction between the individual, groups and society locks out major consumer segments and may not lead to solutions that can sustain motivation over a long period.

Paradigm of Raising Awareness and Changing Attitudes. PT-based approaches are typically designed following the paradigm that raising awareness and changing attitudes are the main drivers for behavior change. Research, however, has shown that behavior change does not necessarily come from raised awareness [32], nor from a change in attitude [33]. In fact, the actual influence of awareness on any change in behavior is usually unclear since other factors may also have played a [unknown] role [6]. Empirical results suggest that some behaviors are induced neither by attitude nor intention; on the contrary, observations have shown that "although the attitude-tobehavior connection is not very substantial, the behavior-to-attitude link has been shown to be quite strong" [33, p. 253]. For example, "people may recycle simply as a result of changes in municipal waste collection services, without ever having decided that recycling is a good thing" [23, p. viii].

A too narrow focus on awareness and attitude, assuming purely reactive consumers, misses the power on consumer's decisions deriving from a broad field of various influences. As pointed out before, influences derive from structures into which consumers are integrated such as communities, major corporations, rules and regulations. Moreover, purely focusing on awareness and attitude misses the motivational power given by pro-active engagement opportunities.

Inherent Technology Paternalism. PT-based approaches applied in the field of sustainability are mostly based on the implicit assumption that the designers of the application start from objective criteria for "sustainable" behavior and are able to operationalize them in the application context. The evaluation of the consumer's actions according to these criteria is delegated to the system in order to automatically rate the impact of an action and to recommend alternatives. In this process, "the designer seems to be de facto more knowledgeable about sustainability than the users of PSSs" [6, p. 953]. This attitude is referred to as "technology paternalism". Paternalism is a concept used in ethics, describing an attitude involving imposition of solutions to assumed problems on other persons even without their consent.

The underlying ethical dilemma arises from the fact that an imposed solution on one side clearly "violates the autonomy of the other person". On the other hand, "by not imposing [the solution] one may not do the best possible in the interest of the other" [34]. 


\subsection{Potential for Improvement}

PT persuades people rather than creating opportunities for negotiation, reflection and self-conviction. Thereby, the question arises "where to draw the fine line between persuasion and manipulation." [15, p. 634]. Furthermore, PT assumes "that the user has already understood and accepted the larger reason that the technology inscribes" [7, p. 61].

Consequently there is room for innovation to tap a much greater potential for motivating and supporting sustainable consumption through ICT- based solutions.

\section{Gamification}

In the field of residential energy consumption, systems with the goal of motivating pro-environmental behaviors have evolved from eco-feedback technologies for electricity consumption such as early ambient displays (e.g. The Power Aware Cord [35]) and sophisticated remotely accessible In-Home Displays (IHD) to more actively persuasive systems such as EcoIsland, "a system for persuading users to reduce $\mathrm{CO}_{2}$ emissions" [36, p. 59]. Recently, especially because of the motivational and engaging character of games, gamification-based design has become of increased interest in this field.

In the following we are going to outline basic design requirements to overcome the limitations of PT to sustainable consumption. Gamification-based approaches have been developed in different fields. The requirements may not be transferable to all of them e.g. approaches to prevent adolescents from substance abuse and relationship violence [37] or to encourage engagement in online debate systems [38].

In section 3.1 we give background information on gamification with a focus on motivational aspects of games being of interest for gamification-based approaches to sustainable consumption. In section 3.2 we provide an outline of basic requirements for these systems to overcome the limitations of PT.

\subsection{Background}

Whereas the field of gamification has already been implicitly introduced over the last decades, its terminology is new [39]. One of the most conclusive and most frequently cited definitions of gamification is given by Deterding et al.: "Gamification refers to the use (rather than the extension) of design (rather than game-based technology or other game-related practices) elements (rather than full-fledged games) characteristic for games (rather than play or playfulness) in non-game contexts (regardless of specific usage intentions, contexts, or media of implementation)." [40, p. 13].

This definition gives a formal understanding of gamification, it does not restrict the aim or scope of a gamification-based system. So far more common in loyalty programs such as frequent flyer programs, recently, the field of gamification has expanded beyond such programs and gained interest in another area: motivating and engaging consumers. 
The goal of gamification in this newer area is to engage consumers in the process of developing their own behaviors, and it does this by "the process of using game thinking and game mechanics" [39, p. 9].

Gamification does not necessarily require interaction with an ICT system, as the examples of frequent flyer programs and discount stamps show. However, in the following, we will implicitly refer to gamification as an ICT-based approach.

Playing or Gaming? According to Deterding and colleagues, playing (from the Greek term "paidia") refers to a free form of expression, allowing improvisational recombination of different behaviors and meanings, in contrast to gaming (from the Latin term "ludus") [40]. However, there are no generally accepted definitions of these concepts, even after millennia of thinking and talking about them [41]. In the words of Lehman and Witty: "The whole truth' regarding play cannot be known until the whole truth regarding life itself is known, for play is; not an isolated phenomenon." [42, p. 7]. We will rely on the following tentative definitions of the concept of game:

- "A game is a problem-solving activity, approached with a playful attitude'. Thereby, 'play' is defined as 'manipulation that satisfies curiosity." [41, p. 37].

- "A game is a rule-based formal system with a variable and quantifiable outcome, where different outcomes are assigned different values, the player exerts effort in order to influence the outcome, the player feels attached to the outcome, and the consequences of the activity are optional and negotiable." [43, p. 5]

Game Elements. Schell, based on various definitions of games, identifies ten elements of a game: "Games are entered willfully, have goals, have conflict, have rules, can be won and lost, are interactive, have challenges, create their own internal value, engage players and are closed, formal systems" [41]. Similarly, McGonigal proposes four defining traits which all games have in common: "a goal, rules, a feedback system and voluntary participation" [44, p. 20].

The Motivational Power of Games. Despite there is no consensus on how to define "game", there is a wide consensus about the motivational power of games [45]. Motivational aspects are manifold, their power depends on diverse influences such as context, interface design and genre, and they can be introduced by different means. We will elaborate on crucial motivational aspects in the following subsections.

Flow. According to McGonigal, the power of a good game is that it "motivate[s] us to participate more fully in whatever we're doing" [44, p. 125]. In fact, researchers in the area of neuropsychology have found evidence that playing video games can release Dopamine, a neurotransmitter, which "may be involved in learning, reinforcement of behavior, attention, sensorimotor integration and activation of the pleasure circuit" [46, p. 266]. This intense neurochemical activation in our brain and body while playing a good game [44] has been referred to as state of flow. Flow expresses a state of being completely absorbed in what one does [47]. It can be experienced within a small channel between anxiety and boredom and depends on 
personal (player) skills in regard to a challenge (Fig. 2). Flow is individually experienced and can happen in any kind of situation, including non-game activities.

According to this concept, a person (player) in position A (Fig. 2) will try to improve her or his skills in order to reach the channel of flow for the chosen challenge. This is illustrated in Fig. 2 by the solid arrow pointing from position A to the right. A second possibility would be to choose an easier challenge (illustrated by the dashed arrow pointing from position A downwards (Fig. 2)), but in practice this solution seems to be less likely [47]. By further improving the skills, a challenge might be mastered and become boring. In this scenario, the person (player) moves away from the flow channel and ends up at position B (Fig 2). To go back to the channel of flow, a harder challenge has to be chosen, indicated by the solid arrow pointing from position B upwards (Fig 2).

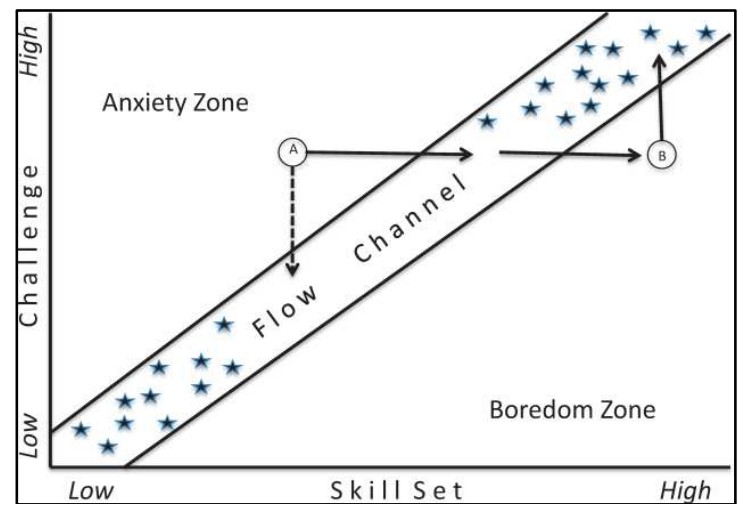

Fig. 2. Flow (Source: author, based on [47])

Player Types. Based on the observation that different players find different things fun, Bartle developed an extended concept of different player types. In his basic model he hypothesizes that four different player types do exist. In the extended model he specified the player types by each two sub-types (an implicit and an explicit one) (Table 1) and by the possibility that a player will change type over time. Originally defined for players of Multi-User-Dungeon (MUD), a multiplayer real-time virtual world, his framework is useful for various kinds of games.

Model of Skill Acquisition. Based on the model of skill acquisition [51], [52], people seek mastery in whatever they do (e.g. losing weight). The underlying assumption is, that by "acquiring a skill by means of instructions and experience" people "normally pass through five developmental stages" - novice, competence, proficiency, expertise and mastery [51, p. 0].

Cooperation and Competition. Intra-group solidarity (cooperation) and inter-group competition are two key aspects of human behavior [23] and two basic mechanisms used in game design [53]. Whereas, in competition, "individuals or groups seek to outplay others in accordance with the game rules" [54, p. 7], cooperation encourages 
participation and collaboration; "the goal is not to win as a player but as a team of players" [55, p. 253]. Both goal structures "can be widely implemented in a nongaming context" [53, p. 2005]. Moreover, it is also possible to compete with oneself in order to become better now and in the future, compared to the past.

The high relevance of cooperation in motivating players has been demonstrated by Massive Multiplayer Online Role-Playing Games (MMORPG) [56], cooperative games [55], and collaborative game-based learning [54]. An online survey related to player motivation provided data from 3,000 MMORPG players and identified teamwork as an important social component for player motivation [56]. Results of a background questionnaire about the preference between cooperative and competitive games done in Canada revealed that $55 \%$ of the 60 6-16 years old kids preferred cooperative games, while $77 \%$ preferred games with both elements [55].

Learning. Learning, whether deliberately or inadvertently, is a key factor in behavior change. "In the social learning system, new patterns of behavior can be acquired through direct experience or by observing the behavior of others" [57, p. 3]. Together with modeling our behavior on what others do, this is suggested by research to be a more promising way for achieving behavior change than raising awareness is [23]. People learn most effectively from models who are seen as more successful by them [57], attractive to them, influential to them or alike them [23]. Collaborative gamebased learning builds on social learning and is described as a game that "involves more than one player in gameplay with the pedagogical intention to promote cooperative learning between those engaged in the game." (p. 4). Key factors for motivating collaborative learning are cooperation and a sense of belonging [54].

\begin{tabular}{|l|l|l|}
\hline \multicolumn{1}{|c|}{$\begin{array}{c}\text { Original Player Types } \\
\text { [48] }\end{array}$} & \multicolumn{1}{c|}{$\begin{array}{c}\text { New Implicit Types } \\
\text { [49] }\end{array}$} & \multicolumn{1}{c|}{$\begin{array}{c}\text { New Explicit Types } \\
\text { [49] }\end{array}$} \\
\hline $\begin{array}{l}\text { Achievers want to gather as } \\
\text { many points as possible and } \\
\text { level up. }\end{array}$ & $\begin{array}{l}\text { Opportunists look around for } \\
\text { things to do and if they see an } \\
\text { opportunity, they take it. They } \\
\text { avoid obstacles. }\end{array}$ & $\begin{array}{l}\text { Planners set a goal and aim to } \\
\text { achieve it. They perform actions as } \\
\text { part of a larger plan and work around } \\
\text { obstacles. }\end{array}$ \\
\hline $\begin{array}{l}\text { Explorers prefer to expose } \\
\text { the game's internal } \\
\text { machinations. }\end{array}$ & $\begin{array}{l}\text { Hackers seek to discover new } \\
\text { phenomena by going where their } \\
\text { fancy takes them and have an } \\
\text { intuitive understanding of the } \\
\text { virtual world. }\end{array}$ & $\begin{array}{l}\text { Scientists actively form theories and } \\
\text { nest knowledge and seek to explain } \\
\text { phenomena. }\end{array}$ \\
\hline $\begin{array}{l}\text { Socializers like to connect } \\
\text { with other people. }\end{array}$ & $\begin{array}{l}\text { Friends "interact with people they } \\
\text { know well already, have a deep } \\
\text { understanding of them, and accept } \\
\text { their quirks and foibles." }\end{array}$ & $\begin{array}{l}\text { Networkers make an effort to find } \\
\text { people with whom to interact, learn } \\
\text { from, and hang out. }\end{array}$ \\
\hline $\begin{array}{l}\text { Killers like to impose } \\
\text { themselves on others. }\end{array}$ & $\begin{array}{l}\text { Griefers love to attack and get in } \\
\text { your face. Their vague aim is to } \\
\text { acquire a substantial bad } \\
\text { reputation. }\end{array}$ & $\begin{array}{l}\begin{array}{l}\text { Politicians manipulate people subtly } \\
\text { through } \\
\text { foresight. They want to contribute to } \\
\text { and }\end{array} \\
\text { fhe community and get a substantial } \\
\text { good reputation. }\end{array}$ \\
\hline
\end{tabular}

Table 1. Illustration of Bartle's Player Types (based on [50]) 


\section{First Attempts to Introduce Gamification into the Field of Sustainable Consumption}

Early approaches including gamification-based ideas have mostly been developed as prototypes with aspects from PT, eco-feedback technology, game design and other related fields. The dominating application domain for these systems is found in the home context, in particular with regard to domestic energy consumption. In the following, we introduce two examples of prototypes, which often are referred within literature and one example from the industry, all containing gamification-based aspects.

\subsection{Domestic Energy Consumption}

EcoIsland [36] is a "game-like application" addressing the final goal of reducing domestic energy consumption within a household. In regard to a target $\mathrm{CO}_{2}$ emission level, which is set by each family, rising energy consumption is correspondingly visualized on an IHD by a rising sea level eventually threatening a virtual island. Avatars representing the household members inhabit the island. Two possibilities for stopping the sea level from rising are provided; either through reduction of energy consumption or by acquiring emission rights. In order to reduce energy consumption, household members can select actions from a list of actions predefined by the system designer (such as turning down the air-conditioning). A lower sea level makes it possible to sell emission rights to other islands (neighboring households). The virtual earnings can be use to decorate the island. All neighbors are able to see all islands and all taken actions.

\section{2 $\mathrm{CO}_{2}$ Emission Caused by Transportation}

UbiGreen [2] is a mobile phone application which semi-automatically senses means of transportation and provides corresponding information on the behavior indicating $\mathrm{CO}_{2}$ emissions caused by taken choices. Small rewards are given to those who take "green" choices (e.g. taking public transportation, carpooling or walking). Feedback is provided over two different interfaces between which users can choose. One shows a tree and the other a polar bear on a small iceberg. Both tree and iceberg indicate green choices. Progress is shown by a sequence of images. At the beginning the tree has no leaves and the iceberg, on which the polar bear is standing is very small. When green means of transportation are chosen, the tree gets more leaves and in the final stage bears apples. Correspondingly, the iceberg gets bigger and harbors more animals (fish, seals, other polar bears), finally the last picture shows northern lights above a large group of polar bears. 


\subsection{Eco-friendly Driving}

Toyota built a special feature into their Prius line [3], a miles-per-gallon meter, showing the average miles per gallon since the last fill-up. This feature is claimed to be the beginning of a trend called hypermiling [58], a competition where car drivers try to drive as many miles as possible on one gallon. To do this they use different techniques, such as adjusting their driving style, driving behind trucks or driving when it's not windy.

\section{Requirements for a Gamification-based Approach to Sustainable Consumption}

By "[attempting] to harness the motivational power of games and apply it to realworld problems" [59, p. 1], gamification offers opportunities for overcoming limitations of PT in the domain of sustainable consumption.

Gamification by itself neither guides the designer through the identification of relevant game design elements nor teaches how to use, apply, and combine these elements (among themselves and within the context). "Yet despite the parallel increase in research on fun, entertainment, and motivation in video game play, we are still in want of theoretical models of the motivational pull of game elements" [60, p. 2].

In fact recent gamification-based approaches have been criticized for just randomly applying game elements, neither considering the application context nor the user's background. This is why they "will fail to drive participation and sustain user engagement" [61, p. 6]. Moreover, as pointed out in the previous section, current gamification-based approaches usually inherit some fundamental limitations of PTbased approaches.

We therefore define four requirements that can help constraining the search space for good design in the field of gamification-based approaches to sustainable consumption. This set of requirements is derived from the results and perspectives discussed in the preceding sections.

\subsection{Requirement 1: Respecting Consumers as Individuals}

Respecting consumers as individuals by enabling skill acquisition and multiple levels and types of challenges in order to provide multifaceted user experiences

The model of skill acquisition [51], [52], the concept of flow [47] and the framework of different player types [49] together, picture the dynamics and diversity of individual consumers. Put in simple terms, consumers include different player types who acquire different skills by different means. Consumers choose these means according to their desired level of challenge with the goal of maintaining themselves in the state of flow.

This dynamic is a driving force of engagement within individuals, and has to be taken into account by gamification-based approaches for sustainable consumption. 
Such an approach considers societal, cultural and demographic aspects (e.g., regulations, knowledge, restrictions, location of living, number of children, nonavailability of alternatives...) influencing consumers' decisions. This means that consumers should not be treated as users to be merely informed, but as social actors who are engaged in the process of sustainable consumption.

\subsection{Requirement 2: Respecting the Consumers' Autonomy}

Respecting the consumers' autonomy by designing game dynamics that authorize users to define their own sub-goals and the avenues for reaching their goals (e.g. according to time, place, action, device, brand)

Direct experience is one important factor in learning, which itself is a powerful factor in changing behaviors. Developing more sustainable behaviors with regard to consumption by allowing consumers to design their own routes and choose their own speed (e.g. by defining sub-goals) instead of following predefined paths and system structures, thus respecting consumers' autonomy, is an important part of gamificationbased approaches for sustainable consumption.

This approach enables consumers to obtain experience alongside the core (offering an indirect path to sustainable consumption) and gives individual meaning to actions (and to their output). Moreover, consumers are part of the process of solution building. This is both a powerful motivational element and a bottom-up approach generating knowledge for the whole field of sustainable consumption.

\subsection{Requirement 3: Introducing the Social Level}

Enabling social interaction by providing possibilities for (normative) comparisons of individual achievements and the opportunity to share own experiences and suggestions with others in order to enable social learning

Gamification-based approaches to sustainable consumption only make sense when taken to the social level. By doing so, the isolated view of actions can be expanded by relating them to the context in which they are carried out.

This overcomes the rational approach of measurable aspects by adding meaning to specific actions. Normative comparisons expand multifaceted user experiences by introducing additional game elements, such as competition. Moreover, the sharing of suggestions and experiences might trigger more solutions and strategies for sustainable consumption and lead to spillover effects.

\subsection{Requirement 4: Enabling Collective Action}

Enabling group experiences by introducing game elements on a group level in order to expand user experiences and providing more possibilities for engagement, particularly intra-group cooperation and inter-group competition 
This requirement differs from requirement 3 by specifically addressing the experience of collective action. By introducing the possibility of collective actions, gamificationbased approaches enable the achievement of group goals. The combination with requirement 2 , e.g. reaching group goals while setting individual sub-goals, widens the user experience and provides an additional motivational aspect. Moreover, by taking collective actions, synergetic effects become visual to individuals. This is relevant because single actions taken by individuals are often perceived as a drop in the ocean.

\section{Conclusion and Future Work}

We have discussed limitations of PT we consider relevant in the field of sustainable consumption, particularly

- the focus on measurable effects,

- the assumption of rational choice,

- an insufficient account of individual differences and social context,

- the paradigm of raising awareness and changing attitudes,

- the inherent technology paternalism.

Gamification-based solutions have great potential for engaging consumers in sustainable consumption, but are not per se immune to the limitations of PT. For this reason, a design framework for gamification-based solutions is needed. Based on existing evidence from the literature in the fields of PT, eco-feedback technology, game design, psychology and related fields, we defined four basic design requirements for gamification-based approaches supporting sustainable consumption. The four basic design requirements are:

1. Respecting consumers as individuals

2. Respecting the consumers' autonomy

3. Introducing the social level

4. Enabling collective action

These requirements are intended to provide guidance to the designer who wants to go beyond the limitations of PT. The definition of these basic requirements is a first stepping-stone toward a design framework for gamification-based approaches to sustainable consumption.

A complete framework will provide more guidance to the designer in selecting features depending on the application context, including cultural factors. Empirical research will be needed to develop aspects of such a design framework by developing and testing hypotheses about the effects of specific types of gamification on motivation in a sustainability context. The most central issue for a process that could be called "motivation design for sustainable consumption" is how to create a link between the physical and social reality. Sustainable consumption is rooted in physical reality, it is about using energy or buying material goods, while these actions are embedded in existing social practices. Gamification adds a virtual world that creates a 
new link between the two spheres and supports the transformation of practices by using elements of games. Future research based on empirical studies will help to reveal the success factors of such an approach.

\section{References}

1. UNEP: ABC OF SCP: Clarifying Concepts on Sustainable Consumption and Production. (2010).

2. Froehlich, J., Dillahunt, T., Klasnja, P.: UbiGreen: investigating a mobile tool for tracking and supporting green transportation habits. Proceedings of the 27th international conference on Human factors in comuting systems - CHI 09. 1043-1052 (2009).

3. Fogg, B.: Creating persuasive technologies: an eight-step design process. Persuasive. (2009).

4. Foster, D., Lawson, S., Blythe, M., Cairns, P.: Wattsup?: Motivating reductions in domestic energy consumption using social networks. Proceedings of the 6th Nordic Conference on Human-Computer Interaction Extending Boundaries - NordiCHI '10. pp. 178-187. ACM Press, New York, New York, USA (2010).

5. Mankoff, J., Fussell, S.R., Dillahunt, T., Glaves, R., Grevet, C., Johnson, M., Matthews, D., Matthews, H.S., Mcguire, R., Thompson, R., Shick, A., Setlock, L.: StepGreen . org : Increasing energy saving behaviors via social networks. 1-8 (2009).

6. Brynjarsdottir, H., Håkansson, M.: Sustainably unpersuaded: How persuasion narrows our vision of sustainability. CHI 2012. pp. 947-956 (2012).

7. Bogost, I.: Persuasive games: The expressive power of videogames. MIT Press (2007).

8. Simões, J., Redondo, R.D., Vilas, A.F.: A social gamification framework for a K-6 learning platform. Computers in Human Behavior. 1-9 (2012).

9. LinkedIn, https://www.linkedin.com/.

10. ResearchGate, https://www.researchgate.net.

11. OPOWER: Better information, motivation, and control for all, http://opower.com/.

12. The Science Behind Radar Speed Signs as Neurobehavioral Activators, http://www.radarsign.com/the-science-behind-radar-speed-signs-as-neurobehavioralactivators/.

13. Fogg, B.: Persuasive computers: perspectives and research directions. SIGCHI conference on Human factors in computing. pp. 225-232 (1998).

14. Fogg, B.: Persuasive Technology: Using Computers to Change what We Think and Do. Morgan Kaufmann (2003).

15. Spahn, A.: And lead us (not) into persuasion...? Persuasive technology and the ethics of communication. Science and engineering ethics. 18, 633-50 (2012).

16. Froehlich, J., Findlater, L., Landay, J.: The Design of Eco-Feedback Technology. Proceedings of the 28th international conference on Human factors in computing systems CHI 10. pp. 1999-2008. ACM Press (2010).

17. McCracken, G.: Culture and Consumption: A Theoretical Account of the Structure and Movement of the Cultural Meaning of Consumer Goods. Journal of Consumer Research. 13, 71-84 (1986).

18. Penn, D.J.: The Evolutionary Roots of Our Environmental Problems: Toward a Darwinian Ecology. The Quarterly Review of Biology. 78, 275-301 (2003).

19. Soron, D.: Sustainability, self-identity and the sociology of consumption. Sustainable Development. 18, 172-181 (2010). 
20. Costanza, E., Ramchurn, S.D., Jennings, N.R.: Understanding domestic energy consumption through interactive visualisation. Proceedings of the 2012 ACM Conference on Ubiquitous Computing UbiComp '12. pp. 216-225. ACM Press, New York, New York, USA (2012).

21. Kazmi, A.H., Grady, M.J.O., Hare, G.M.P.O.: Non-intrusive Identification of Electrical Appliances. 190-195 (2013).

22. Figueiredo, M., Almeida, A. De, Ribeiro, B.: Non-intrusive Residential Electrical Consumption Traces. 51-58.

23. Jackson, T.: Motivating Sustainable Consumption. (2005).

24. Benkler, Y.: Law, Policy, and Cooperation. (2008).

25. Wikipedia, http://www.wikipedia.org/.

26. Nicholson, S.: A User-Centered Theoretical Framework for Meaningful Gamification. In: Martin, C., Ochsner, A., and Squire, K. (eds.) Proc. GLS 8.0. pp. 223-230. ETC Press, Pittsburgh, PA (2012).

27. Stets, J., Burke, P.: A sociological approach to self and identity. Handbook of self and identity. 1-48 (2003).

28. Greenwald, A.G., Pratkanis, A.R.: The Self. Handbook of social cognition. pp. 129-178 (1984).

29. Triandis, H.C.: The Self and Social Behavior in Differing Cultural Contexts. Psychological Review. 96, 506-520 (1989).

30. Mead, G.: THE SELF. Mind Self and Society from the Standpoint of a Social Behaviorist. pp. 1-65 (1934).

31. Baumeister, R.F., Leary, M.R.: The need to belong: desire for interpersonal attachments as a fundamental human motivation. Psychological Bulletin. 117, 497-529 (1995).

32. Yun, R., Scupelli, P., Aziz, A., Loftness, V.: Sustainability in the Workplace: Nine Intervention Techniques for Behavior Change. LNCS 7822 - Persuasive Technology. pp. 253-265 (2013).

33. Zanna, M.P., Olson, J.M., Fazio, R.H.: Self-Perception and Attitude-Behavior Consistency. Personality and Social Psychology Bulletin. 7, 252-256 (1981).

34. Hilty, L.M.: Ehtical Issues in Ubiquitous Computing - Three Technology Assessment Studies Revisited. Presented at the (2014).

35. Gustafsson, A., Gyllenswärd, M.: The power-aware cord: energy awareness through ambient information display. CHI 2005. pp. 1423-1426 (2005).

36. Takayama, C., Lehdonvirta, V., Shiraishi, M., Washio, Y., Kimura, H., Nakajima, T.: ECOISLAND: A System for Persuading Users to Reduce CO2 Emissions. 2009 Software Technologies for Future Dependable Distributed Systems. 59-63 (2009).

37. Schoech, D., Boyas, J.F., Black, B.M., Elias-Lambert, N.: Gamification for Behavior Change: Lessons from Developing a Social, Multiuser, Web-Tablet Based Prevention Game for Youths. Journal of Technology in Human Services. 31, 197-217 (2013).

38. Tolmie, P., Chamberlain, A., Benford, S.: Designing for reportability: sustainable gamification, public engagement, and promoting environmental debate. Personal and Ubiquitous Computing. (2013).

39. Zichermann, G., Cunningham, C.: Gamification by Design. O’Reilly Media (2011).

40. Deterding, S., Dixon, D., Khaled, R., Nacke, L.: From Game Design Elements to Gamefulness : Defining “Gamification.”MindTrek'11 Proceedings of the 15th International Academic MindTrek Conference: Envisioning Future Media Environments. pp. 9-15. ACM (2011).

41. Schell, J.: the Art of Game Design: A Book of Lenses. CRC Press (2008).

42. Lehman, H., Witty, P.: The psychology of play activities. (1927). 
43. Juul, J.: The game, the player, the world: looking for a heart of gameness. Digital Games Research Conference Proceedings. 1-13 (2003).

44. McGonigal, J.: Reality Is Broken: Why Games Make Us Better and How They Can Change the World. Penguin Press HC, The (2011).

45. Ryan, R.M., Rigby, C.S., Przybylski, A.: The Motivational Pull of Video Games: A SelfDetermination Theory Approach. Motivation and Emotion. 30, 344-360 (2006).

46. Koepp, M.J., Gunn, R.N., Lawrence, a D., Cunningham, V.J., Dagher, a, Jones, T., Brooks, D.J., Bench, C.J., Grasby, P.M.: Evidence for striatal dopamine release during a video game. Nature. 393, 266-8 (1998).

47. Csikszentmihalyi, M.: FLOW: The Psychology of Optimal Experience. Harper Perennial Modern Classics (1990).

48. Bartle, R.: HEARTS, CLUBS, DIAMONDS, SPADES: PLAYERS WHO SUIT MUDS, http://www.mud.co.uk/richard/hcds.htm.

49. Bartle, R.: Virtual Worlds : Why People Play. 1-16 (2005).

50. Hong, K.J.: Player Types: Watch for Moving Targets, http://blog.kennethjhong.com/2012/08/player-types-watch-for-moving-targets.html.

51. Dreyfus, S.E., Dreyfus, H.L.: A five-Stage Model of The Mental Activities Involved in Directed Skill Acquisition. 0-18 (1980).

52. Dreyfus, S.E.: The Five-Stage Model of Adult Skill Acquisition. Bulletin of Science, Technology and Society. 24, 177-181 (2004).

53. Peng, W., Hsieh, G.: The influence of competition, cooperation, and player relationship in a motor performance centered computer game. Computers in Human Behavior. 28, 2100 2106 (2012).

54. Romero, M., Usart, M., Ott, M., Earp, J., de Freitas, S., Arnab, S.: LEARNING THROUGH PLAYING FOR OR AGAINST EACH OTHER? PROMOTING COLLABORATIVE LEARNING IN DIGITAL GAME BASED LEARNING. ECIS 2012 Proceedings. Paper 93. pp. 7-17. AIS Electronic Library (AISeL) (2012).

55. Seif El-Nasr, M., Aghabeigi, B., Milam, D., Erfani, M., Lameman, B., Maygoli, H., Mah, S.: Understanding and evaluating cooperative games. Proceedings of the 28th international conference on Human factors in computing systems - CHI '10. pp. 253-262. ACM Press, New York, New York, USA (2010).

56. Yee, N.: Motivations for Play in Online Games. Cyberpsychology \& Behavior : the impact of the Internet, multimedia and virtual reality on behavior and society. 9, 772-775 (2006).

57. Bandura, A.: Social Learning Theory. General Learning. pp. 1-46 (1971).

58. Gamification. What are some car companies that use game mechanics? In which models and how?, http:/www.quora.com/Gamification/What-are-some-car-companies-that-usegame-mechanics-In-which-models-and-how.

59. Lee, J.J., Hammer, J.: Gamification in Education: What, How, Why Bother? Academic Exchange Quarterly. 15, 1-5 (2011).

60. Deterding, S.: Situated motivational affordances of game elements : A conceptual model. CHI 2011. pp. 1-4 (2011).

61. Kankanhalli, A., Taher, M., Cavusoglu, H., Kim, S.: Gamification: A New Paradigm for Online User Engagement. Thirty Third International Conference on Information Systems, Orlando. 1-10 (2012). 